\title{
Self-aligned nematic crystallization of poly(oxypropylene)amine intercalated silicates on toluene/water interface
}

\author{
Rong-Jer Lee ${ }^{\mathrm{a}}$, Jiang-Jen Lin ${ }^{\mathrm{b}}$, Wen-Tung Cheng a,* \\ a Department of Chemical Engineering, National Chung Hsing University, Taichung 402, Taiwan, ROC \\ b Institute of Polymer Science and Engineering, National Taiwan University, Taipei 10617, Taiwan, ROC
}

\section{A R T I C L E I N F O}

\section{Article history:}

Received 3 August 2007

Received in revised form 25 January 2008

Accepted 15 March 2008

Available online 28 March 2008

\section{Keywords:}

Interfaces

Nanostructure

Adsorption

Crystallization

\begin{abstract}
A B S T R A C T
A self-assembly stacking on liquid-liquid interface of intercalated smectite silicates results in nematic structure and self-aligning nature, was revealed in this study. The stacking crystalline of polyoxypropylene amine intercalated montmorillonite, with a diameter of $200 \mathrm{~nm}$ and a length more than $10 \mu \mathrm{m}$, was found. Polyoxpropylene amine with hydrophobic polymer coil renders its $\left\langle S^{2}\right\rangle$ radius of gyration to expand dspacing of silicate clay to $58 \AA$. The texture rearrangement is not only applied to interlayer structure but also to inter-particles structure [010] of clays. The crystallization is formed through the primary organo-clays align on interface and undergoes a face-to-face stacking.
\end{abstract}

(c) 2008 Elsevier B.V. All rights reserved.

\section{Introduction}

Adsorption of organoammonium onto clay minerals has been studied extensively because both organoamine and clays are common components in nature. The main objective of these procedures is usually to increase the interlayer spacing, allowing the synthesis of materials with larger pore widths than those obtained with the more usual methodology of PILC preparation [1-4]. Montmorillonite layered silicate clay can be hydrophobically modified by an ion exchange reaction with alkylammonium, the intercalation reaction of positive charged alkylammonium and negative charged silicate [5-8]. The cationic head group of the alkylammoniun portion prefers to absorb on the layer surface and the aliphatic backbones radiate stretch away the neighboring silicate plates [9]. The interlayer distance is generally functionalized as the backbone chain length at several Å to $100 \AA$, with the acidified poly(oxypropylene)amine intercalation [10]. Crystal powder swelled and expanded its [001] dimension without affecting other two dimensions was shown in XRD patterns. The primary structure of these particles has a dimension below $100 \mathrm{~nm}$ $[1,12]$. The cationic polymer coil was confined in the inter-layered silicates space and also absorbed on the corona surface of primary particle, with an adhering force of ion bridges between the polymeric

\footnotetext{
* Corresponding author.

E-mail address: wtcheng@dragon.nchu.edu.tw (W.-T. Cheng).
}

ammonium and clay plate surface [11-13]. The long range electrostatic attraction forces don't support the macroscopic order texture formation of montmorillonite platelets, the suspension and solid film is anisotropic agglomeration in random orientation [14-16]. To get orderly alignment nematic phase from smectite clay, special treatment is necessary $[17,18]$, such as spin-coat concentrated suspension to an radial aligned thin film on quartz [19].

In this work, the hydrophobic acidified poly (oxypropylene) amine intercalated montmorillonite was well dispersed into clear toluene solution, and allowed to concentrate in toluene/water interface to form a thin film structure through solvent evaporation. A special mineral nematic crystalline was obtained by self-assembling of $58 \AA$ A-spacing organo-silicates. Compare to the reported techniques such as spin coating or concentrated suspension to get crystalline mesophase, this self-alignment crystallization in liquid-liquid interface has advantages to provide nano-metric control of organo-inorganic hybrid materials.

\section{Experimental section}

The preparation for the wide d-spacing silicates was reported previously [10]. Typically, $\mathrm{Na}^{+}$-montmorillonite with $\left(\mathrm{Na}^{+}-\mathrm{MMT}, 10 \mathrm{~g}\right.$, cationic exchange capacity $\mathrm{CEC}=1.15$ mequiv/g) was vigorously dispersed in $1 \mathrm{l}$ of de-ionized water at $80{ }^{\circ} \mathrm{C}$. The slurry was added with amine salts prepared from the poly(propylene oxide)diamine Mw 2000 (POP) (23 g, $11.5 \mathrm{mmol})$ and equivalents of hydrochloric acid in water. After being vigorously stirred at $80{ }^{\circ} \mathrm{C}$ for $5 \mathrm{~h}$, the precipitation was collected at room temperature, washed thoroughly with warm water/ethanol, and dried in vacuum. The intercalated MMTs were 
Table 1

Lyotropic self-align stacking of poly(propylene oxide)amine intercalated montmorillonite (MMT) and properties

\begin{tabular}{|c|c|c|c|c|}
\hline Materials & $\begin{array}{l}\text { Weight fraction } \\
\text { organics } / \text { silicate }\end{array}$ & $\begin{array}{l}\text { Basal } \\
\text { spacing } \\
\AA\end{array}$ & Crystallization $^{c}$ & $\begin{array}{l}\text { Specific } \\
\text { birefringence } \\
\text { texture }\end{array}$ \\
\hline $\mathrm{POP}^{\mathrm{d}}$ & $100 / 0$ & - & Amorphous & None \\
\hline MMT & $0 / 100$ & 12.4 & $1-3 \mu \mathrm{m}$ & None \\
\hline $\begin{array}{l}\text { MMT }^{e} \text { Lyotropic } \\
\text { concentrated on } \\
\text { interface }\end{array}$ & $0 / 100$ & 19.3 & $1-3 \mu \mathrm{m}$ & None \\
\hline POP/MMT & $63 / 27$ & 58.0 & $3-4 \mu \mathrm{m}$ & None \\
\hline $\begin{array}{l}\text { POP/MMT }{ }^{\mathrm{b}} \text { Lyotropic } \\
\text { concentrated on } \\
\text { interface }\end{array}$ & $63 / 27$ & 42.0 & $\begin{array}{l}10-40 \mu \mathrm{m} \\
\text { rod-like }\end{array}$ & Nematic \\
\hline
\end{tabular}

a Weight fraction: organic composition/silicate (measured by TGA).

b Basal spacing by X-ray diffraction.

c Based on cross polarizer optical microscope and SEM.

d Poly(propylene oxide)diamine Mw 2000.

e Materials dispersed in water was poured on toluene/water interface and set to dry.

analyzed by X-ray diffraction, to have a d-spacings of $58.0 \AA$, and assigned as POP/MMT intercalated crystalline.

The self-assembly process in the water/toluene interface was performed by dispersing POP/MMT in toluene, carefully pouring to the surface of distilled water. The same solution was allowed to evaporate the upper toluene phase completely at room temperature to obtain thin dry film, and evaporation of toluene takes at least14 days to dry (Fig. 3). The film was further dried at $80{ }^{\circ} \mathrm{C}$ for $5 \mathrm{~h}$ before the examination by polarized optical microscope, Scanning Electron Microscope (SEM) and Electron Spectroscopy for Chemical Analysis (ESCA). The properties of prepared materials were shown in Table 1.

In order to correlate the concentration effect with basal spacing, various concentrations of polyoxypropylene amine were added to intercalate to adjust the d-spacing of the pillared clay, amine/CEC ratio of $0.2,0.5,0.6,0.65,0.8,1.0$, and 2.0 were prepared, the intercalated MMTs were analyzed by X-ray diffraction in showing d-spacings of $17.8,18.0,18.4,18.3,58.0,58.0$ and $57.0 \AA$ A , accordingly. Correspondingly, the wide gallery spacing encapsulated the POP-amines from $20 \%$ to $80 \%$ weight fractions, estimated by TGA(Perkin Elmer).The thermogravimetric data of organo-clay are determined with the highest calcination temperature until $800{ }^{\circ} \mathrm{C}$.

The crystalline texture of the hybrid polyelectrolyte compositions were determined by the analysis of X-ray powder diffractograms, which involved the identification and semi-quantification of the characteristic peaks of the minerals in the sample.. The native montmorillonite showed a broad peak at $2 \theta$ indexed to the [001] plan, corresponding to interlayer distance $(d)$ of 14.0 A. The X-ray diffraction patterns were obtained with nickel filtered $\mathrm{Cu} K \alpha$ radiation on a Shimadzu diffractometer.

The compositions of clay and intercalated composites were estimated by FTIR. The infrared spectra of montmorillonite [21] showed the main bands at $3447 \mathrm{~cm}^{-1}$ attributed to $\mathrm{O}-\mathrm{H}$ stretching $\mathrm{OH}$ hydroxyl groups of water associated to the hydration and the silanol groups bonded to the native matrix and the stretching vibrations corresponding to $\mathrm{Si}-\mathrm{O}-\mathrm{Si}$ and $\mathrm{Si}-\mathrm{O}-\mathrm{Al}$ bonds that appeared at $997 \mathrm{~cm}^{-1}$. Infrared spectra were recorded on a Perkin Elmer spectrophotometer in $4000-400 \mathrm{~cm}^{-1}$ range, being the solid sample in $\mathrm{KBr}$ pellet, with $4 \mathrm{~cm}^{-1}$ of resolution.

\section{Results and discussion}

\subsection{Clay intercalation of polyoxypropylene amine}

The chemical compositions of the intercalated polyoxypropylenes were analyzed by FTIR spectrophotometer in $4000-400 \mathrm{~cm}^{-1}$ range, the adsorption spectrum of intercalated MMT compared to the background MMT. The intercalated materials showed changes in intensities of these bands and an occurrence of new ones at $2930-2859 \mathrm{~cm}^{-1}$ due to asymmetric and symmetric $\mathrm{C}-\mathrm{H}$ stretching bands, respectively. However, the absorptions associated with $\mathrm{N}-\mathrm{H}$ stretching vibrations are in the same region of silanol absorptions. The band presences near 1600 and $1450 \mathrm{~cm}^{-1}$ corresponding to symmetric deformation vibration of the $\mathrm{NH}_{2}^{+}$suggested that amino groups should be protonated, resulting from the acidified interaction of polyoxypropylene amine with $\mathrm{OH}$ of silicate. The band $1630 \mathrm{~cm}^{-1}$ assigned to $\delta(\mathrm{HOH})$ show water is presence in MMT and intercalated MMT.

Thermogravimetric data of intercalated polyoxypropylene amine are shown in Table 1 . The mass losses had been determined until $800{ }^{\circ} \mathrm{C}$ since this was the highest calcination temperature of the poly (oypropylene)amine. With the additional amine/CEC ratios keep increasing from 0.5 to 2.0 , all the adsorption amounts of poly (oxypropylene) amine are lower than the additional amounts and the maximum POP adsorption is saturated at 0.8 of POP/CEC ratio (Fig. 1). For the additional POP/CEC ratio below 0.65 , the adsorption of poly (oxypropylene) is kept stable at 0.23 of POP/CEC. There is a turning point at $0.8 \mathrm{POP} / \mathrm{CEC}$ additional ratio during the synthesis, the adsorption ratios increased significantly to 0.67 . These results indicate the intercalation reaction went through ion exchange route, the cationic adsorption is restricted to be below the charge balance point, and the amine molar ratio will not be higher than the sodium content of clay, it is 2.5 wt.\% for neat $\mathrm{Na}^{+} \mathrm{MMT}$.

As montmorillonite intercalation with hydrophobic polyoxypropylene, the sodium ion is expelled out of cell gap and the concentration is decreased to $0.1 \mathrm{wt} \%$ after 0.8 molar ratio of POP/ CEC intercalated, the presence of polyoxypropylene amine modify the electrical double layer of clay silicate's surface through electrolyte depleting. The thickness of double layer $k^{-1}$, is function of electrolyte concentrations Cs, $\left(k^{-1}\right)^{2} \sim 1 / \mathrm{Cs}$, here Cs is the sodium ion concentration inside interlayer [12]. It is assumed, the additional (POP/CEC) ratio increased over the range of 0.65 to 0.8 where the sodium ion is mostly drained. So, when the polyoxypropylene exceed the turning point, the Basal spacing correlated to the polymeric electrical double layer is significantly expands.

The double layer structure thickness evolved as polyoxypropylene amine concentration over critical amount at $0.8 \mathrm{POP} / \mathrm{CEC}$, where the (ether/CEC) unit ratio number is higher then 24. The hydrophobic tendency of poly(oxypropylene)diamine bulk coil increase as higher concentration, which has an effect to expel water solvent and hyrated ions in the electrical double layer of clay platelet. The polymeric molecules extend its random polymeric coil and hence dilute the hydrated ion of that diffused in electrical double layer.

The orderly column hybrid of POP/MMT was shown on WXRD diffraction(Fig. 2b), compared to MMT(Fig. 2a) which has only one

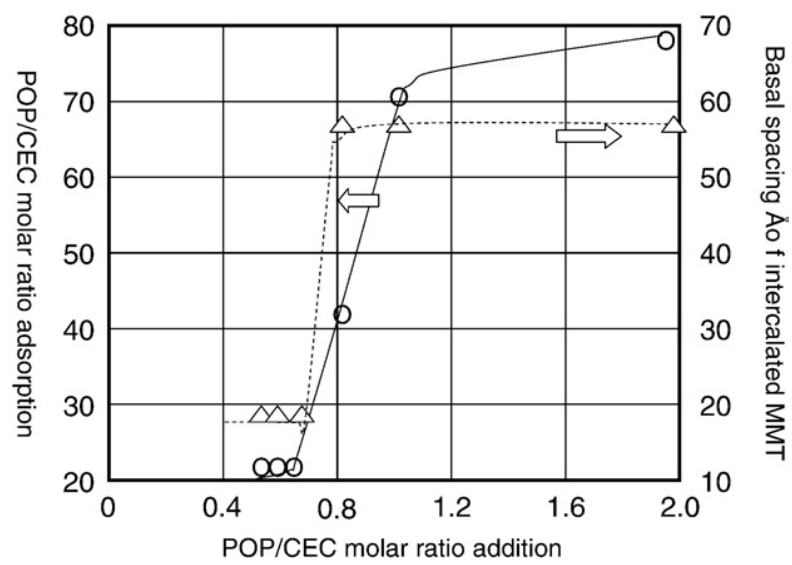

Fig. 1. POP/CEC molar ratio of POP adsorption into MMT (solid line) and Basal spacing of the intercalated MMT correlated to POP/CEC ratio (dotted). 


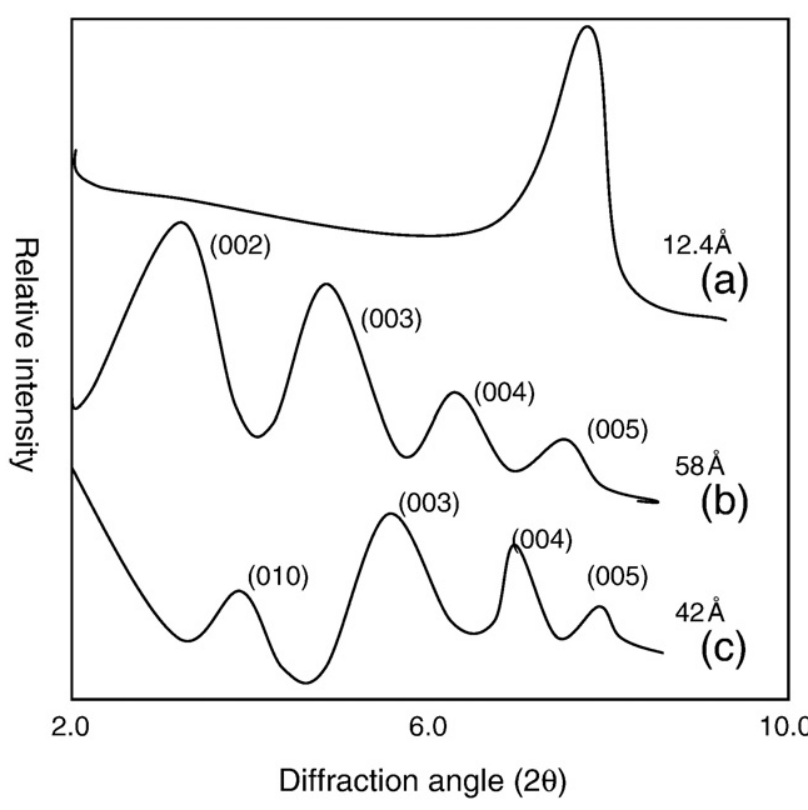

Fig. 2. X-ray diffracting powder pattern of (a) Clay $\mathrm{Na}^{+}-\mathrm{MMT}$ (b) POP/MMT aggregation (c) POP/MMT crystallized on toluene/water interface.

broad diffraction peak with d-spacing $14 \AA$ A. The interplatelet basal spacing $d$, is equivalent to

$d \sim 4<S^{2}>^{1 / 2} \ldots$.

where $\left\langle\mathrm{S}^{2}\right\rangle$ is the gyration radius of polymeric coils absorbed on silicate surface. This interpretation has been recently confirmed by molecular dynamics simulations where a strong layering behavior with a bilayer liquid-like polymer arrangement has been found in Table 2, and can also evolve towards a more ordered arrangement of clay by increasing the chain length [1]. Consequently, the interactive processes of d-pacing expansion involving the equilibrium of the polymer random coil extension and the interlamellar attraction. Compared with the [001] peak for MMT clay, it is clear that this peak with increasing intensity is coming from the expanded clay layers after polyoxypropylene amine adsorption and the basal spacing is found further expanded to $58.0 \AA$ A for POP/CEC ratio is 0.8 .

\subsection{Self assembly of intercalated clay on liquid/liquid interface}

Intercalation of montmorillonite with poly (propylene oxide) amine (POP) obtained from a toluene dispersible hybrid composite shows no specific birefringence texture before and after drying in bulk solution. The hydrophobic polymer representing 63 wt.\% of the composition in the hybrid dispersed POP/MMT was obtained, a well-

\section{Table 2}

Linear relationship between the poly(propylene oxide) radius of gyration and the interlayer spacing of interclated montmorillonite

\begin{tabular}{llll}
\hline $\begin{array}{l}\text { Molecular weight of poly } \\
\text { (oxypropylene)diamine } \\
\text { (repeat units) }\end{array}$ & $\begin{array}{l}\text { Interlayer } \\
\text { spacing } \\
(\AA)\end{array}$ & $\begin{array}{l}\text { Radius of gyration of } \\
\text { poly(oxypropylene) } \\
\text { diamine }^{\mathrm{a}}\end{array}$ & $\begin{array}{l}\text { Calculated } \\
\text { characteristic factor of } \\
\text { poly(oxypropylene) }\end{array}$ \\
\hline Silicate thickness & 10.0 & - & - \\
D230 (2) & 5.0 & 1.5 & \\
D400(5) & 9.4 & 2.4 & 1.9 \\
D2000(33) & 48.0 & 6.3 & 2.3 \\
D4000(68) & 82.0 & 9.0 & \\
\hline
\end{tabular}

${ }^{\mathrm{a}}$ Bond length (1.54 $\AA$ for $\mathrm{C}-\mathrm{C}$ and $1.43 \AA$ for $\mathrm{C}-\mathrm{O}$ ) and the bond angles (109.6 ${ }^{\circ}$ and $112^{\circ}$ ). The propylene oxide unit length is $2.7 \AA$.

b A double layer poly(propylene oxide)diamine intercalation was assumed. (a)

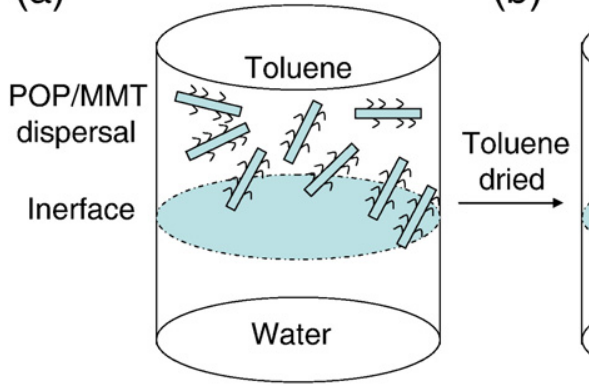

(b)

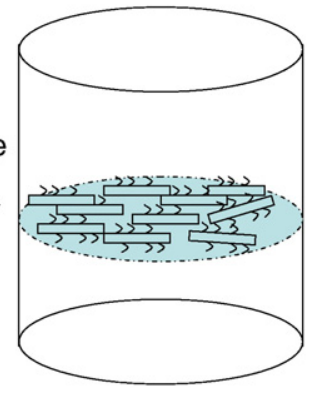

Fig. 3. Schematic graph of $P O P / M M T$ intercalated silicates self-assembling in the toluene/water interface, (a) POP/MMT dispersed in toluene was carefully poured on water surface. (b) self-assembly nematic organo-silicates film was formed on interface after keep it at room temperature for at least14 days.

aligned d-spacing from the Bragg equation with $n=2$ to 5 displays in Xray scattering pattern of dried power (Fig. 2b). Montmorillonite was estimated to have $1 \mathrm{~nm}$ thickness silicate layers stacking in the primary structure with $\sim 100 \mathrm{~nm}$ particle size (Fig. $4 \mathrm{~b})[1,12]$. It was found that the intercalation with polymer backboned cations, the smectite clay do not normally delaminate, it expand only its dimension normal to the face platelet. However, the polymer steric coil on surface also radiate its van der Waals attraction effecting nearby intercalated clay, adds up an average aggregating size of 3-4 $\mu \mathrm{m}$ (Table 1 ).

The intercalated clay with orderly column texture has strong tendency to aggregate to secondary structure. It is expect to perform self-assembly through applying an alignment force. In this study, the interfacial surface tension of toluene/water interface was functioning to align the clay platelets. Since the hydrophobic polyoxypropylene amine intercalated montmorillonite is dispersed easily in toluene, a clear liquid-liquid interface is built up as the toluene solution poured on water and the interface keep stable during the toluene evaporating (Fig. 3). The vapor pressure of toluene at $20^{\circ} \mathrm{C}$ is $22 \mathrm{Torr}$, the dispersed solution was kept at ambient to concentrated on the toluene/water interface, which is essential for the film preparation.

A lyotropic solid film formed, through the silicate template on interface, a high orderly epitaxial structure of POP/MMT is created on the solid film. It shows scattered bright islands under cross polarizer optical microscope and has found a specific nematic texture of birefringence (Fig. 4c). The amphiphilic property of POP/MMT between the interface of toluene and water would align by surface

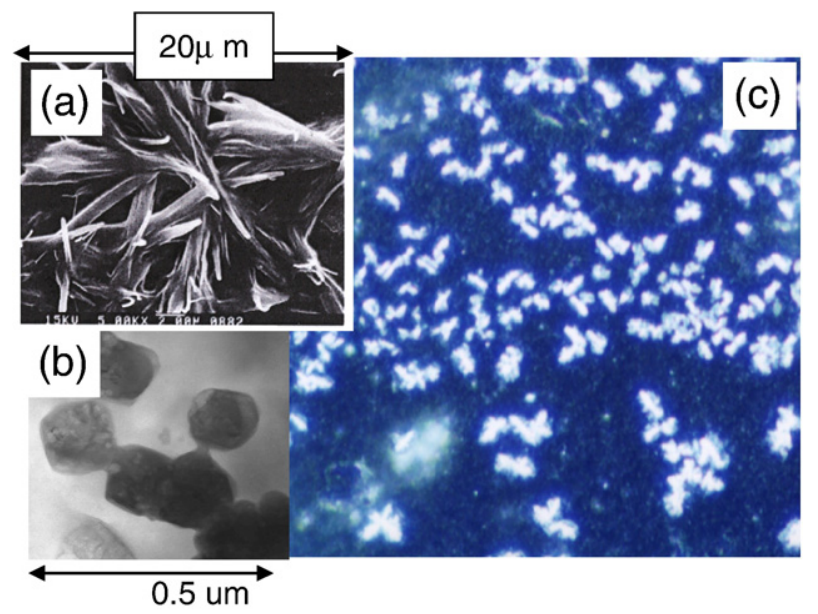

Fig. 4. A lyotropic solid film of poly(propylene oxide)amine intercalated montmorillonite show (a) scattered nematic structure by SEM, (b) primary MMT by TEM, (c) scattered nematic texture by POM. 


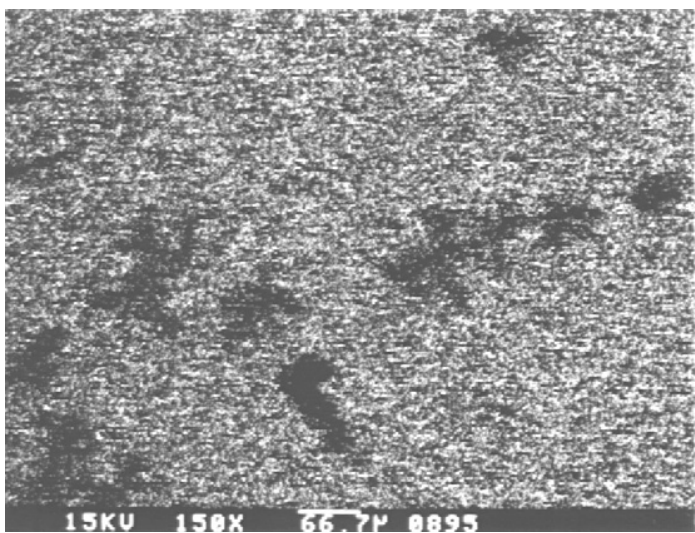

Fig. 5. Element silicon mapping the solid film of poly(propylene oxide)amine intercalated montmorillonite by Electron Spectroscopy for Chemical Analysis.

tension with a face-to-face approaching, and hence stabilized the process of nematic forming, to self-assemble in the interface to form a thin film. Under the examination of optical and electronic microscopy, a high aspect ratio rod-like crystalline, with diameter around $200 \mathrm{~nm}$ and straight length $10 \mu \mathrm{m}$ was observed.

Mapping silicon element of the polyoxypropylene amine intercalated montmorillonite solid film by Electron Spectroscopy for Chemical Analysis (ECSA), silicon element of silicate was found in homogeneous distribution on the film, and the dark shade spots are islanded nematic crystallines (Fig. 5). The secondary $x$-radiation is diffracted by condensed nematic domain crystalline and scattering out of detector's direction. The shape of dark spot is comparable to the optical images of nematic texture in Fig. 4c.

The crystalline phase showed up a new X-ray diffraction pattern of nematic characteristic textures. Fig. $2 c$ shows the X-ray diffracting powder pattern of POP/MMT self-assembly on toluene/water interface. Intercalated silicates of bulk solution show an orderly structure of [001] Bragg peak $n=2$ to 5 and basal spacing 58 A for $n=1$. The pattern (c) of interface dried intercalated silicates represents the secondary structure of the same material after the self-assembling in the toluene/ water interface, showing $n=3$ to 5 , and the basal spacing $42 \AA$ smaller than the original intercalated MMT pattern. The high epitaxial stacking of smectite in bipoar interface affects a high polarity stress on [001] layer silicate and the face-to-face packing, so the basal spacing are smaller than the primary smectite particle (Fig. 2c).

Because the polymer steric coil on surface also radiate its van der Waals attraction effecting nearby intercalated clay [010], the nematic structure formation process include the equilibrium of the polymer random coil $<S^{2}>$ extension and the interparticles attraction is applied to the extraordinary dimension.

The nematic texture of poly(propylene oxide)amine intercalated MMT was proposed that the hybrid should be surface anchoring on interface, it is assuming the face platelets of layered silicate template on toluene/water interface as crystalline seeds. As upper toluene solution layer is drying to be a lyotropic concentrated film of the colloid suspension solution, firstly it drives intercalated MMT to align on the bipolar interface. The primary structure of these particles has a dimension below $100 \mathrm{~nm}$. The cationic polymer coil was not only confined in the interlayered silicates space and also absorbed on the corona surface of primary particle, with an adhering force of ionic bridges between the polymeric ammonium $\mathrm{NH}_{2}^{+}$and clay plate surface. The interaction forces between polycations and clay nano-plates [20] include a long range attraction force that begins to manifest itself at a distance of approximately $120 \mathrm{~nm}$ between cationic polymer and negative charged layer silicate. The bulky $\left\langle\mathrm{S}^{2}>\right.$ polyoxypropylene ammonium adsorbed on the two approaching particles makes anionic charged silicates to attract each other with a face-to-face fashion. The long-range electrostatic attraction makes two plate particles approaching and support the macroscopic order texture formation of montmorillonite platelets, the suspension and solid film is anisotropic agglomeration in orderly orientation. With self-assembly nature, a multilayer of clay-polymer film was prepared by sequential adsorption of polycations and clay particles on interface [010].

The anisotropy crystalline phase implies the clay sheets had experienced a longitudinally ordering formation in the toluene/water bipolar interlayer through different attraction forces. The attraction force between polymeric cation and negative charged silicate platelet is long fetching over the inter-particle range. The absorbed polymeric cations on the surface of montmorillonite primary particles radiate an attraction force to nearby particles. The easily aggregate properties of dispersions are the consequence of long range interactions between the faces of the particles. The polymeric coil bulk chelated on outmost surfaces of smectite clay particles supports an orderly alignment forces as two particles is approaching, the short range van der Waals force between polymeric coils binds the two particles, and produces self assembly column structure by stacking of smectite particles.

\section{Conclusion}

A macroscopic orderly stacking new crystalline is formed from the polyoxypropylene amine modified layered clays. The process involves an essential self-alignment on liquid-liquid interface. A self-assembly stacking crystalline was manipulated by lyotropic concentrated of polyether ammonium intercalated MMT in toluene/water interface The polymer random coil extension and the interlamellar attraction make polycationic charged silicates to attract each other with a faceto-face fashion. To rationalize for the formation of the secondary structure, the silicate platelets had experienced a longitudinally ordering formation on the toluene/water interface through surface alignment. As a result, a rod-like texture was observed under optical and electronic microscopy with a diameter of $200 \mathrm{~nm}$ and a length more than $10 \mu \mathrm{m}$.

\section{References}

[1] M. Alexandre, P. Dubois, Mater. Sci. Eng. 28 (2000) 1

[2] R.A. Vaia, E.P. Giannelis, Macromolecules 30 (1997) 7990

[3] K.A. Carrado, Appl. Clay Sci. 17 (2000) 1.

[4] Y. Umemura, A. Yamagishi, R.A. Schoonheydt, A. Persoons, F.d. De Schryver, Langmuir 17 (2001) 449.

[5] B. Van Duffel, R.A. Schoonheydt, P.C.M. Grim, F.D. De Schryver, Langmuir 15 (1999) 7520.

[6] C. Zeng, L.J. Lee, Macromolecules 34 (2001) 4098.

[7] K. Sonobe, K. Kikuta, K. Takagi, Chem. Mater. 11 (1999) 1089.

[8] K.A. Carrado, L. Xu, Chem. Mater. 10 (1999) 1440.

[9] R.A. Vaia, E.P. Giannelis, Macromolecules 30 (1997) 8000

[10] J.J. Lin, I.J. Cheng, R. Wang, R.J. Lee, Macromolecules 34 (2001) 8832.

[11] A. Szu1cs, T. Haraszti, I. Dékány, J.H. Fendler, J. Phys. Chem. B 105 (2001) 10579.

[12] P.F. Luckham, S. Rossi, Adv. Colloid Interface Sci. 82 (1999) 43.

[13] T.D. Fones, P.J. Yoon, H. Keskkula, D.R. Paul, Polymer 42 (2001) 9929.

[14] P. Kodgire, R. Kalgaonkar, S. Hambir, N. Bulakh, J.P. Jog, J. Appl. Polym. Sci. 81 (2001) 1786.

[15] V.V. Ginzburg, C. Singh, A.C. Balazs, Macromolecules 33 (2000) 1089.

[16] K.A. Carrado, G.W. Zajac, K. Song, J.R. Brenner, Langmuir 13 (1997) 2895

[17] P. Maiti, P.H. Nam, M. Okamoto, N. Hasegawa, A. Usuki, Macromolecules 35 (2002) 2042.

[18] G. Jimenez, N. Ogata, H. Kawai, T. Ogihhara, J. Appl. Polym. Sci. 64 (1997) 2211.

[19] J.C.P. Gabriel, C. Sanchez, P. Davidson, J. Phys. Chem. 100 (1996) 11139.

[20] T. Abe, S. Hayashi, N. Higashi, M. Niwa, K. Kurihara, Colloids Surf. A 169 (2000) 351.

[21] K. Ataka, M. Osawa, Langmuir 14 (1998) 951. 